\title{
Sustainable Management of Water Supply Systems using Multi Criteria Models
}

\section{T.K.N.K. Kumari and N.T.S. Wijesekera}

\begin{abstract}
Twenty-Two management zones spatially distributed in the Piliyandala-Kesbewa Water Supply System undergo problems such as frequent pipe bursting, scaling in old pipes, NonRevenue Water (NRW) issues and pressure drops. Sustainable management of drinking water supply systems mainly depends on organizational growth, service to stakeholders and system sustenance requirements. Therefore, a multi criteria decision support model is most appropriate to manage a water supply system. There are approximately $15 \mathrm{sub}$ criteria associated with water supply system management and some of them are new water connections, monthly bill collection, operation and maintenance, staff salaries and transport facilities, NRW, low pressure, lack of water, water quality, meter defects, water leaks, etc. Considering these, prioritising of water supply management zones requires Multi Criteria Decision Analysis (MCDA) models. A questionnaire survey among 78 water supply managers was used for the model development. Calibrated MCDA model weights for Income Generation, System Sustainability, System Losses and System Reliability are 0.64, 0.20, 0.07 and 0.09, respectively. Verification on modelled priority zones with actual practice exhibited a good agreement while providing hints for improved management. This research clearly demonstrated the suitability and method of development of an Analytical Hierarchical Process (AHP) Multicriteria Decision Model for water supply system management.
\end{abstract}

Keywords: Water management options, Water supply system, MCDA, AHP, Stakeholder assessment, Criteria

\section{Introduction}

A reliable better quality water supply significantly contributes to the national economy of any country. It is important to manage water supply systems to provide a sustainable water supply with acceptable quality at an affordable price in order to match stakeholder requirements. At scheme level, if a Water Supply System (WSS) can be well managed, then there is a high likelihood of ensuring stakeholder satisfaction and simultaneously assuring the sustenance of the scheme as a stand-alone unit. Water supply system management involves the maintenance of a sound pipe network that is suitable to supply water with adequate pressure and quantity within the service extent. Twenty Two management zones spatially distributed in the Piliyandala-Kesbewa WSS undergo problems such as frequent pipe bursts, scaling in the old pipes, high Non Revenue Water (NRW) and low pressure areas in managing water supply systems. Managing a WSS requires careful consideration of organizational expectations, stakeholder satisfaction and system sustenance needs, etc.

Ensuring availability and sustainability of water and sanitation services depends on sustainability of water supply systems and the level of service to stakeholders. Usually WSS managers are interested in financial growth of the organisation, and tend to pay less attention to the service to stakeholders. Therefore, sustainable management of water supply systems is the key to achieve Goal 6 of Sustainable Development Goals. Hence it is important to establish a balanced WSS management by considering Income Generation, System Sustainability, System Losses and System Reliability. In this backdrop, a Multicriteria Decision Analysis (MCDA) model is most appropriate to identify the present situation and then develop a strategy to manage a WSS sustainably [1]. An

\footnotetext{
Eng. T.K.N.K. Kumari, C.Eng. MIE(SL). B.Sc. Eng. Hons (Moratuwa), PG Dip. (Open University), M.Sc.

(Moratuwa)

Chief Engineer (Development), National Water Supply \& Drainage Board, Sri Lanka

Email:kumaritknk@gmail.com

ORCID ID: https://orcid.org/0000-0002-6043-8106

Eng. (Snr. Prof.) N.T.S. Wijesekera, C.Eng., MIECE

(UK), FIE(SL), B.Sc. Eng.Hons (Peradeniya), PG

Dip(Moratuwa), M.Eng. (Tokyo), Ph.D (Tokyo),

Senior Professor, Department of Civil Engineering,

University of Moratuwa, Sri Lanka.

Email: sohanw2@gmail.com

ORCID ID: $h$ ttps://orcid.org/0000-0003-0964-4331
} 
appropriately developed MCDA for the management of WSS will support to improve operational efficiency, quality of services and productivity [2].

The Overall objective of this research is to identify management concerns, evaluate the present prioritisation techniques and develop a MCDA model as a case study, and make recommendations to manage pipe borne water supply systems efficiently and effectively. Piliyandala-Kesbewa WSS (32 $\left.\mathrm{km}^{2}\right)$ was selected as a case study to investigate the present status of system management aspirations at organisational level and the practice at field level. This WSS has 24,309 connections covering an approximate population of 106,960 [3]. This case study also attempts to demonstrate the potential of applying a multi criteria decision model to manage WSSs.

\section{Methodology}

The methodology used for the study is shown in Figure 1. A data collection form was designed for the field survey of system management parameters among NWSDB (National water Supply and Drainage Board) water supply systems and tested with the use of NWSDB middle and senior managers responsible for management of WSS. Main WSS management parameters were identified and refined using this survey. In this, $40 \%$ of the managers in NWSDB representing both categories were used as the stakeholder sample. 78 WSS managers (approximately 38\%) responded to the identification of main parameters and corresponding sub parameters. MCDA model structure was conceptualized using these as main criteria and the sub criteria. The state of the environment for MCDA model is the associated management zones in the Piliyandala-Kesbewa WSS. Management zones comprised the boundaries of the WSS demarcated by considering the number of meter readers in the WSS, pipeline network, number of connections, roadsides, accessibility, elevation of the area, etc. Analytical Hierarchical Process (AHP) developed by Saaty [4] was selected as it provides measures of judgement consistency, derives priorities among criteria and alternatives, while simplifying the determination of preference ratings among decision criteria with the use of pairwise comparisons.
The MCDA model based on AHP for Piliyandala-Kesbewa WSS is shown in Figure 2. During model calibration, parameter weight finalisation for the study area from a number of consistent alternative combinations was done using field data. Model calibration using stakeholder responses identified three consistent weight combinations for the main criteria, namely, Income Generation, System Sustainability, System Losses and System Reliability. The sub criteria identified from the stakeholder surveys were New Water Connections, Monthly Bill Collection, Operation \& Maintenance (O\&M), Salaries \& Overtime, Transport facilities, NRW, Low Pressure, Lack of Water, Water Quality, Defective Water Meters, Leaks in Mains, Leaks in Water Connections, Leaks near Meter, Night Time Leaks, and Stop Valve Leaks. Priority given by stakeholders during the survey was used as the basis for the determination of pairwise comparisons. Graphical comparison of stakeholder priority preferences enabled the identification of three distinct preferential classes. Four combinations which included these three and the simple average of preferences were used to evaluate three AHP options for main criteria. Pairwise ratios and consistency indicators [4], [5] were computed for each combination using a systematic procedure [6]. Except one combination, three combinations resulted in consistent weights for main criteria (Table 1). The consistent combination 3, which originated from the simple average of all stakeholder inputs, was selected as the blend that reflected the typical setting of NWSDB.

Table 1 - The Consistent Main Parameter Combinations

\begin{tabular}{|l|l|l|l|}
\hline \multirow{2}{*}{ Main Parameter } & \multicolumn{3}{|c|}{ Combination } \\
\cline { 2 - 4 } & 1 & 2 & 3 \\
\hline Income Generation & 0.60 & 0.30 & 0.64 \\
\hline $\begin{array}{l}\text { System } \\
\text { Sustainability }\end{array}$ & 0.28 & 0.39 & 0.20 \\
\hline System Losses & 0.07 & 0.27 & 0.07 \\
\hline System Reliability & 0.05 & 0.04 & 0.09 \\
\hline L max Ratio & 4.09 & 4.07 & 4.17 \\
\hline $\begin{array}{l}\text { Consistency } \\
\text { (CR) }\end{array}$ & 0.04 & 0.03 & 0.07 \\
\hline
\end{tabular}

Priority indication for sub criteria did not show a wide variation as in the case for main criteria. Hence, in the absence of any specific interrelationship between options, the use of simple average of responses was considered as 
the most prudent method to be adopted for the computation of pairwise ratios. New water supply connection potential was taken as directly proportionate to uncovered and covered population and inversely proportionate to the prevailing number of connections. Since the bill payments were temporally staggered and inconsistent with the actual field operations, monthly bill collection was taken as proportionate to the consumption of the consumers. O\&M data for Piliyandala-Kesbewa WSS were not available. Customer complaints with regards to the WSS performance reflects the efforts that needed to sustain the system by carrying out proper Operation and Maintenance. Hence, as an alternative, the number of complaints recorded in the NWSDB central database was taken as proportionate to the O\&M efforts. In lieu of the salaries and overtime costs, the staff inputs required to manage the services to the connections in each zone were taken to represent staff salaries and overtime payments. Transport facility cost corresponding to each zone is proportionate to the distance travelled from the Area Engineer Office to the management unit. Water consumed by the scheme was apportioned to management zones according to the number of connections in each zone. System loss computations in NWSDB are carried out on the basis of schemes. System loss values were taken as the NRW computed using the NWSDB formula [7] and apportioned to the number of connections. Averaging of consumer complaints was the method used to evaluate relative System Reliability of each management zone.

Ranking of organizational, managerial and employee preferences with respect to each management zone (state of the environment) was based on measurable quantities related to WSS performance. Hence the ranking of alternatives against each other was based on the parameters computed from field data. As there were no field level guidelines to classify field level service delivery activities according to organisational aspirations, in this study, each sub parameter was linked to one or more service delivery factors and the classifications were confirmed through a consultation of senior NWSDB water supply managers. Verification was carried out by comparing model outputs with the observed spatial variability of field level priority.

\section{Results and Discussion}

\subsection{Model Development}

The literature review and structured questionnaire survey among a majority of water supply managers enabled the identification of four main criteria and 15 sub criteria as the model components for the fulfilment of NWSDB organisational objectives for the management of WSSs.

Main criteria weights computed for the study area showed that there is a significant imbalance in the attention (Table 2) towards each functionality. The relative importance that has been given to system reliability and system losses is very low and amounts to 0.07 and 0.09 , respectively. Results also point to a relative weight of 0.2 for system sustainability associated with the current study area.

The computed sub criteria weights (Table 2) indicated the relative importance given to each sub functionality. Computed weights showed that, with respect to the main criteria of system reliability, the water leaks in total and water quality received a weight of 0.26 , while No water and low pressure were having weights of 0.21 and 0.17 , respectively. This picture about the prevailing considerations facilitates better system management. The priority values computed using the MCDA AHP model and sorted in the ascending order are in Figure 3.

\subsection{Model Validation}

In order to capture the effectiveness of WSS management, it is important to assess whether field level activity prioritisation agrees with the priority computed by the AHP model which is based on aspirations of the higher management.

Attempts to capture the field level priority based on operations, revealed the absence of a systematic documentation to capture a priority order. A notable issue was the reluctance of the field personnel to rank the alternatives by giving an overall service priority even by responding to a questionnaire. However, field level personnel could be persuaded to assign a priority service indicator between 1-10 to each management zone. Therefore, in order to perform a comparison, the modelled weights for each management zone were linearly rescaled. This comparison in Figure 3 reflects a significant disparity between the modelled and field identified priority. Though the slope of the trend lines in Figure 3 points to a similarity in behaviour, it is necessary to note that there is a 
mismatch that requires a remedy for desired sustainable management of the study area.

\subsection{Discussion}

Development of the MCDA AHP model for WSS management posed many problems. Lack of system management guidelines to capture parameters targeting national and organisational objectives, lack of guidelines or documentation to identify field level management indicators to fulfil organizational aspirations, and the lack of guidelines to embed sustainability considerations from the point of view of recipient stakeholders were the main problems. Initially the present study had to overcome the difficulty to conceptualize the model criteria and associated sub criteria by an identification of details through a literature survey and discussions with senior WSS managers.

Hence, it is required to carry out the fine tuning of main and sub criteria after a critical stakeholder analysis and then performing field verification using a structured data collection program. In this study, the stakeholder analysis was restricted to NWSDB WSS engineers. It may be necessary to extend the survey to other stakeholders for a better representation of the institutional aspirations.

The present work also resorted to a stakeholder survey option to assess preferences and then carryout pairwise comparisons. A detailed stakeholder survey for this activity too is appropriate for the verification of responses. Therefore, in order to make more quantified guidance available for the modellers, NWSDB must perform area specific and objectivespecific studies as demonstrated by this research, this studied stakeholder responses in great detail to note varying stakeholder prioritization trends leading to several consistent Saaty AHP combinations. However, it was noted that a simple average of stakeholder views could be used as a suitable solution. An evaluation of the collected data reflected a close similarity of responses that may have led to this possibility. In future studies, it is prudent to appropriately select stakeholders and then perform a further evaluation on the use of simple averaging of stakeholder responses for the determination of weights from similar MCDA models.

The model outputs reflected that there is a disparity between the organisational aspirations and field application. In case of MCDA AHP models such as the present one, the evaluation of pairwise preferences using performance data requires the availability of established relationships between the criteria and performance data. In this study, a rational set of assumptions were required to evaluate the performance of sub criteria against the main criteria. Such assumptions also contribute to the disparity between model and field application priorities. The assumptions used in the research need to be established for better performance evaluations using similar modelling tasks.

Objective of WSS managers must be to identify the spatial distribution of priority among management zones. Therefore, one major requirement is the objective based demarcation of management zones. Presently there is lack of guidelines to follow for the purpose of demarcating spatial extents. Field survey carried out for this research revealed that the present spatial demarcations in WSS are mostly on meter-reader convenience, and then modified by trial and error. In this context, uniformity in decisions could not be identified. Hence the field work for this study required many discussions with the engineers, engineering assistants and meter-readers to identify manageable clusters for MCDA model development. As resources become competitive, it is very important to use models to manage systems. Therefore, in such anticipation, it is necessary for water supply managers to identify the actual parameters that govern the spatial management of WSS. Hence planning and monitoring activities of the KesbewaPiliyandala WSS must focus on the determination of spatial boundaries and associate parameters with the intention of sustainable system management.

Model Calibration and Verification required the conversion of stakeholder responses and Areaengineer's priority order values to suit Saaty's AHP scale. In this study, a linear aggregation system was considered as sufficient. It must be noted that this may require strengthening. Hence it is important to develop system management guidelines and then conduct direct pairwise comparison assessments by using employees conversant with multi criteria modelling. In case of field management levels, the field level priority values were restricted to a scale of 1- 10 for convenience. This study emphasises the importance of establishing management practices clearly reflecting objectives at various levels of management hierarchy and the degree of detailing to embed in assessment scales. This would strengthen and improve field data collection accuracies. The 
non uniformity in weight conversions, the gaps in criteria determination, and field level constraints for obtaining verification data would have led to the mismatch of MCDA model output and the actual situation (Figure 3). The clustering of zones also requires detailed evaluation to improve the MCDA model.

The present study identified four main criteria and 15 sub criteria that are considered as adequate for the fulfilment of NWSDB organisational objectives to sustainably manage similar water supply systems. Therefore, the highlight is the revelation of functionalities that are presently in focus within the organisation, thus paving the way for policy makers to evaluate their adequacy and inadequacies to effect appropriate interventions for holistic system management to achieve the organisational objectives.

The main criteria weights derived from stakeholder data demonstrated a heavy inclination on Income Generation and a very low attention to System Losses and System Sustainability.

This significant importance given to income generation requires a detailed investigation since it reflects the existence of an imbalance hinting a substantial deficiency in management process. Lower priority to these two criteria identified during modelling should be looked at from the point of view of sub criteria which are linked to each Main criterion. The low weightage values given to NRW and system weakness can be easily noted from the MCDA management tree. This evaluation can be further extended to spatial extents and then capture the preference given to specific areas. Hence, the management of NWSDB has to immediately assess the situation and provide resources to strengthen system sustainability minimise losses and ensure a higher reliability. One important outcome from the present study is the need for the organisation to initiate early stakeholder consultations between the management staff of the organisation and operation staff in the field to determine the appropriate system priority criteria.

\section{Conclusions}

A MCDA model for the management of the WSS for Piliyandala - Kesbewa was successfully developed. Though the trend line showing the spatial variability of priority from MCDA model indicated a similarity between the area engineer's prioritisation, the priority values exhibited that there are gaps that require attention to ensure the sustainable management of the studied water supply system. The AHP model incorporating stakeholder pairwise combinations revealed that average of stakeholder preferences would be a satisfactory starting indicator for model development. Field identified priority indicators of each management zone differed from the AHP indicators demonstrating lack of guidelines for the management at field level and a clear link of objectives at various levels of management. The criteria weights for Income Generation, System Sustainability, System Losses and System Reliability were $0.64,0.20,0.07$ and 0.09 , respectively. Very low priority for System Losses and System Reliability reflects a deficiency in System Management.

MCDA model hierarchy and weights provide a clear indication for water supply organisations to evaluate whether management objectives are suitably achieved during system operations. This research clearly demonstrated the suitability, potential and method of development of an AHP based MCDA Model for WSS Management. This study recommends to carry out other system studies in a similar manner while overcoming the current weakness with respect to the guidelines and stakeholder assessment.

\section{Acknowledgement}

The Support received by the UNESCO Madanjeet Singh Centre for South Asia Water Management, Department of Civil Engineering, University of Moratuwa, Sri Lanka and National Water Supply \& Drainage Board is gratefully acknowledged.

\section{References}

1. Abrishamchi, A., Ebrahimian, A., Tajrishi, M., and Mariño, M. A., "Case Study: Application of Multicriteria Decision Making to Urban Water Supply," J. Water Resour. Plan. Manag., vol. 131, no. 4, pp. 326-335, 2005, doi: 10.1061/(ASCE)0733-9496(2005)131:4(326).

2. Roy, B., Slowiñski, R., and Treichel, W., "Multicriteria Programming of Water Supply Systems for Rural Areas," JAWRA J. Am. Water Resour. Assoc., vol. 28, no. 1, pp. 13-31, 1992, doi: 10.1111/j.1752-1688.1992.tb03151.x.

3. S. L. D. of C. and Statistics, "Census of Population and Housing - Population Tables - 2012," no. 65, pp. 2-5, 2014, [Online]. Available:

file:// C:/Users/Lasith/AppData/Local/M 
endeley

Ltd./Mendeley

Desktop/Downloaded/Sri Lanka

Department of Census and Statistics - 2014 -

Census of Population and Housing Population Tables - 2012.pdf.

4. Budescu, D. V., Zwick, R., and Rapoport, A., "A Comparison of the Eigenvalue Method and The Geometric Mean Procedure for Ratio Scaling," Appl. Psychol. Meas., vol. 10, no. 1, pp. 69-78, 1986, doi: $10.1177 / 014662168601000106$.

5. Okeola, O. G., and Sule, B. F., "Evaluation of Management Alternatives for Urban Water Supply System using Multicriteria Decision Analysis," J. King Saud Univ. - Eng. Sci., vol. 24, no. 1, pp. 19-24, 2012, doi: 10.1016/j.jksues.2011.07.004.

6. Kumari, T. K. N. K., “Multicriteria Decision Modelling for Management of Water Supply System in the Piliyandala - Kesbewa Water Supply System, Colombo District, Sri Lanka."Master Thesis. 2015.

7. Malithi, W. P., "Impacts of Non Revenue Water on the National Water Supply and Drainage Board and Methods to Minimize it," Proceedings of the 7th International Conference on Sustainable Built Environment. 2016.

8. White, G. P., "The Implementation of Management Science in Higher Education Administration," Omega, vol. 15, no. 4, pp. 283-290, 1987, doi: 10.1016/03050483(87)90016-8.

9. Özkan, B., BaŠligil, H., and Şahin, N., "Supplier Selection using Analytic Hierarchy Process: An Application from Turkey," Proc. World Congr. Eng. 2011, WCE 2011, vol. 2, pp. 1160-1165, 2011. 


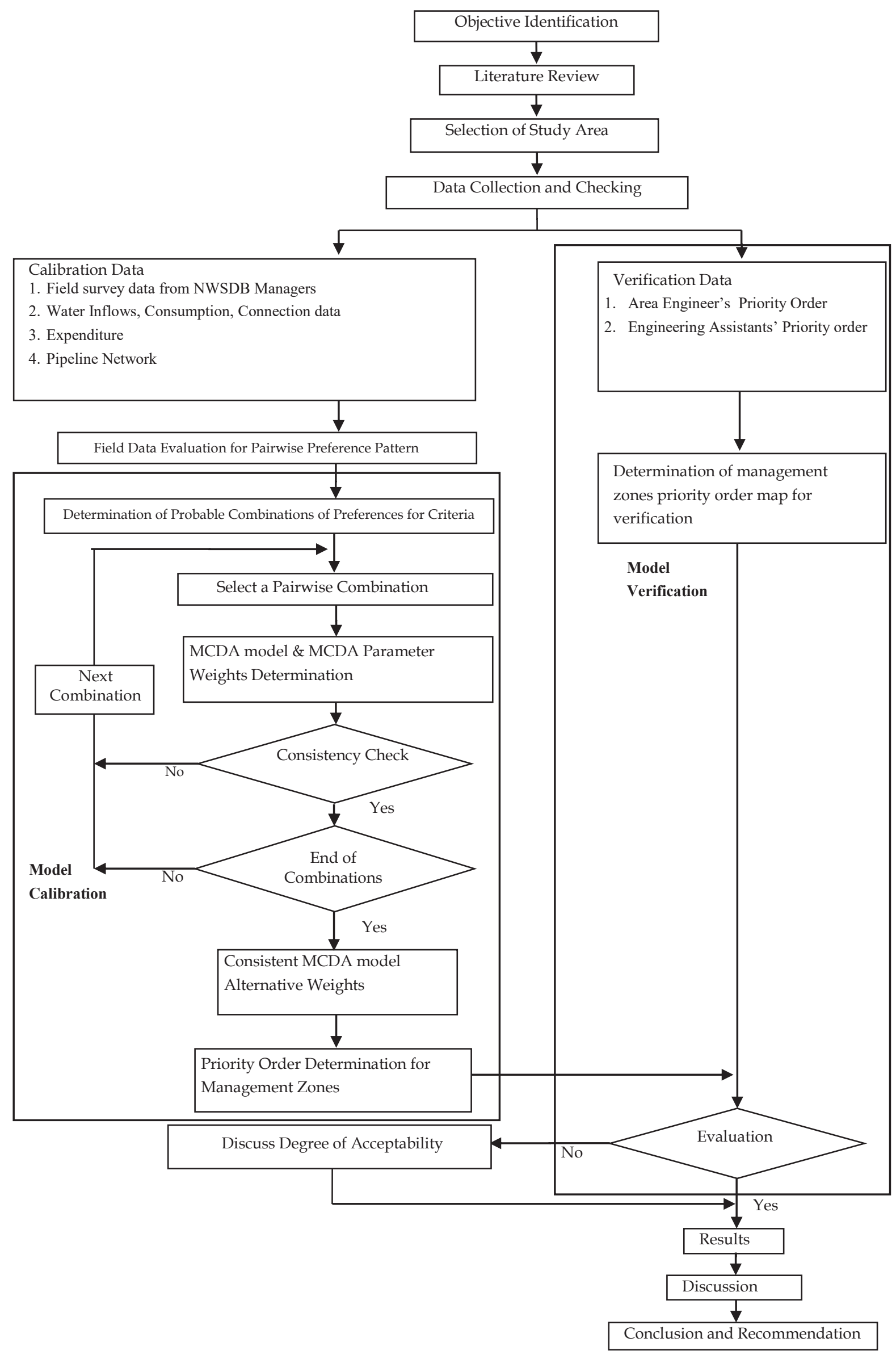

Figure 1 - Methodology Flow Chart 


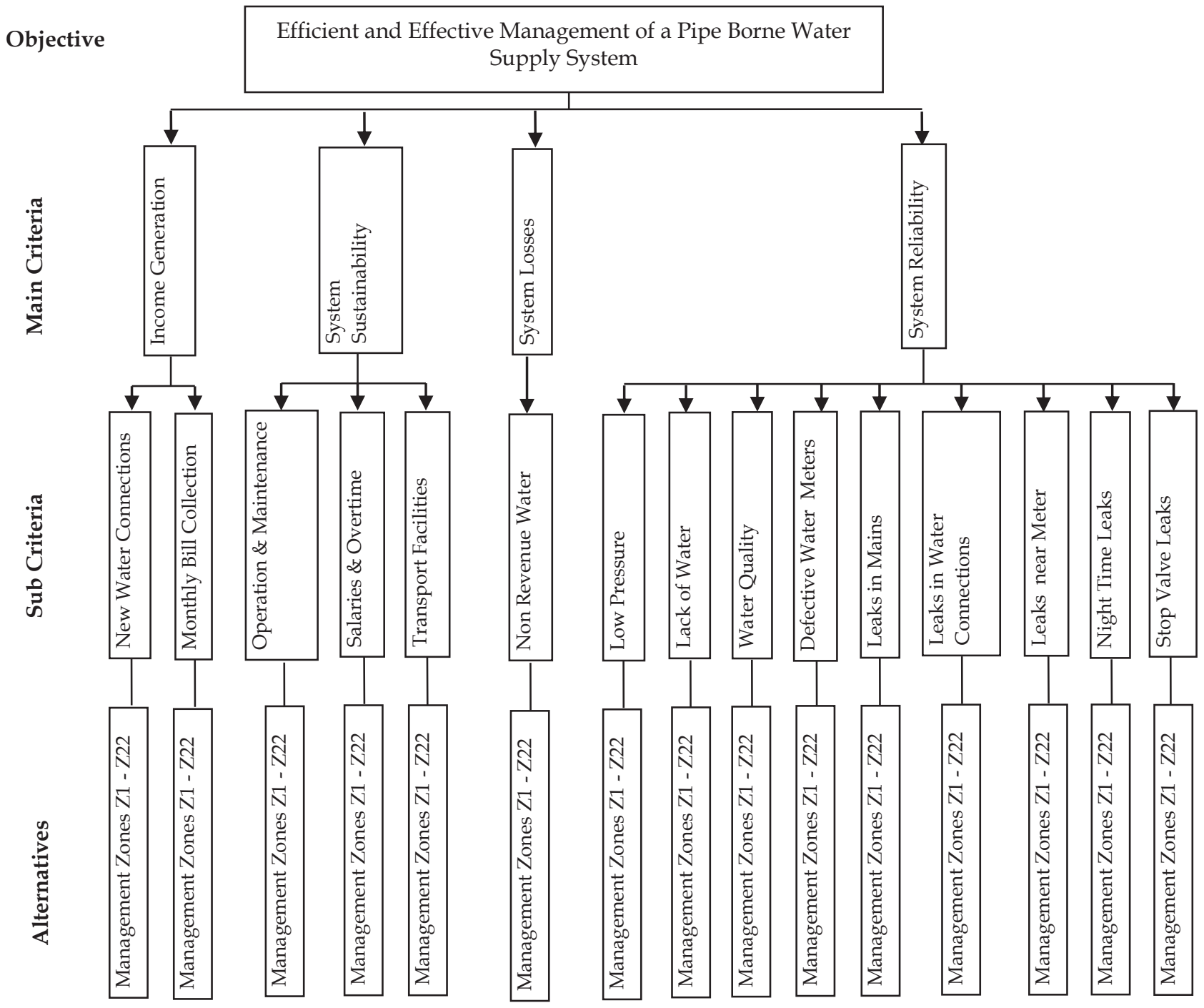

Figure 2 - MCDA Model for the Piliyandala - Kesbewa WSS

Table 2 - Main and Sub Criteria AHP weights for Combination 3

\begin{tabular}{|c|c|c|c|}
\hline \# & Main Criteria & Sub Criteria & Priority \\
\hline \multirow{2}{*}{1} & \multirow{2}{*}{ Income Generation 0.64} & Bill Collection & 0.51 \\
\hline & & New Connections & 0.49 \\
\hline \multirow{3}{*}{2} & \multirow{3}{*}{ System Sustainability 0.20} & Operation \& Maintenance & 0.71 \\
\hline & & Salaries and Overtime & 0.23 \\
\hline & & Transport & 0.06 \\
\hline 3 & System Losses 0.07 & Non-Revenue Water (NRW) & 1.00 \\
\hline \multirow{9}{*}{4} & \multirow{9}{*}{$\begin{array}{l}\text { System Reliability } \\
0.09\end{array}$} & Water Quality & 0.26 \\
\hline & & No water & 0.21 \\
\hline & & Low Pressure & 0.17 \\
\hline & & Leak - Mains & 0.12 \\
\hline & & Defective Meters & 0.10 \\
\hline & & Leak - Connections & 0.05 \\
\hline & & Leak - Night time & 0.04 \\
\hline & & Leak - Near meter & 0.03 \\
\hline & & Leak -Stop valve & 0.02 \\
\hline
\end{tabular}




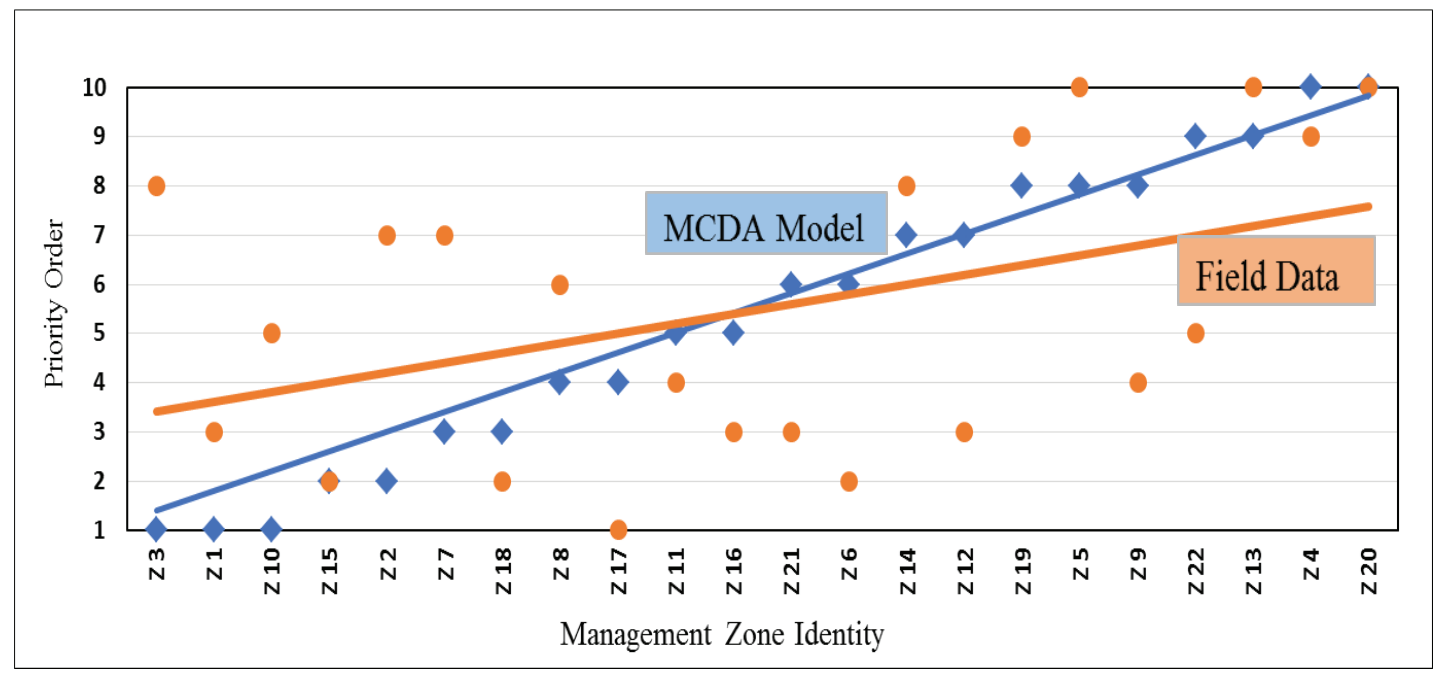

Figure 3 - Comparison of Priority Order Behaviour for Model Verification 